\title{
Unusual and voluminous pulmonary trunk aneurysm
}

\author{
Michele Correale $\cdot$ Riccardo Ieva $\cdot$ Andrea Igoren Guaricci • \\ Matteo Di Biase
}

Received: 9 April 2011/Accepted: 20 May 2011/Published online: 3 June 2011

(C) SIMI 2011

\section{Case}

A 65-year-old woman, with hypertension and dyslipidemia, was admitted to our department because of effort dyspnea. The electrocardiogram and physical examination were normal. Transthoracic two-dimensional echocardiography (2DE) showed left and right cardiac chambers with normal dimensions and function (LVEF 65\%), mild concentric left ventricle hypertrophy, mild valvular pulmonic stenosis (the continuous-wave Doppler showed a peak velocity of $2.93 \mathrm{~m} / \mathrm{s}$, which is consistent with a systolic gradient of $34 \mathrm{mmHg}$ ) and aneurysmal dilatation of the main pulmonary artery with extension to the bilateral main branches (Fig. 1). An exercise ECG test showed an inappropriate increase in heart rate and blood pressure at low exercise workloads without ST segment abnormalities. The exercise level was inadequate to test cardiac reserve. A computed tomography (CT) coronary angiography was performed. It showed a voluminous aneurysm $(77.6 \mathrm{~mm})$ of the pulmonary artery (Fig. 2), without other cardiac abnormalities.

\section{Discussion}

Pulmonary artery aneurysm (PAAs) — defined as PA dilation greater than $4 \mathrm{~cm}$-is a rare condition, regardless of the cause. The etiology of PAAs can be congenital or acquired. Congenital aneurysms are usually associated with congenital heart diseases causing pulmonary hypertension,

M. Correale $(\bowtie) \cdot$ R. Ieva - A. I. Guaricci · M. Di Biase Department of Cardiology, "Ospedali Riuniti”OO.RR, University of Foggia, Viale L Pinto, 1, 71100 Foggia, Italy e-mail: opsfco@tin.it and persistent ductus arteriosus is the most frequent. Other congenital causes include atrial and ventricular defects.

Acquired causes can be idiopathic or associated with other processes, such as infections (tuberculosis, syphilis), traumatisms, pulmonary valvular stenosis, or diseases affecting collagenous tissue [1, 2].

In rare cases, when the PAA is not due to a functional or structural anomaly of the cardiovascular system, it is known as an idiopathic PAA.

Clinical presentation of a PAA varies. It can be asymptomatic, being a chance finding in a chest X-ray study, echocardiography or computed tomography. In symptomatic patients, dyspnea, hemoptysis and chest pain are the most frequent complaints $[1,3]$.

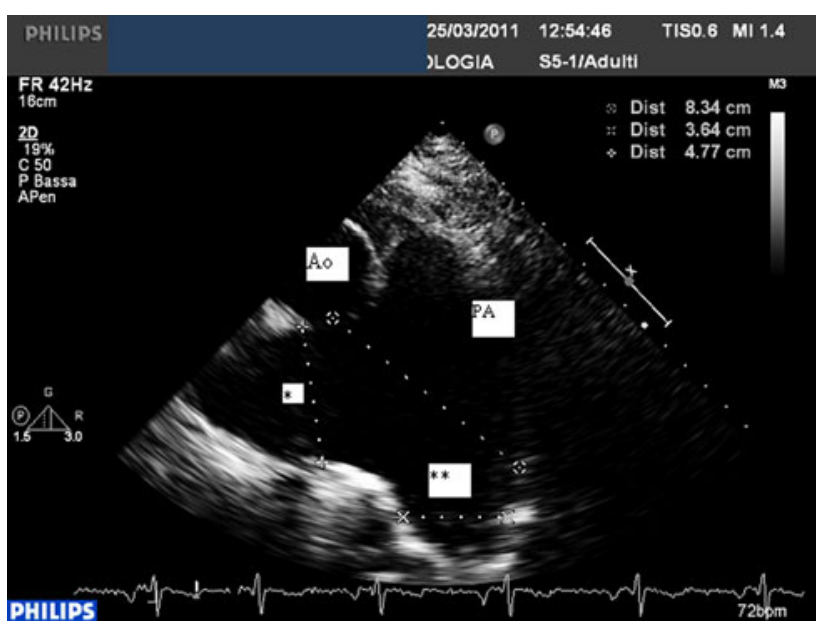

Fig. 1 Two-dimensional echocardiography: parasternal short-axis view showing the measurement of the pulmonary artery aneurysm of approximately $8 \mathrm{~cm}$. (Ao aortic valve; $P A$ main pulmonary artery; *right pulmonary artery; **left pulmonary artery) 

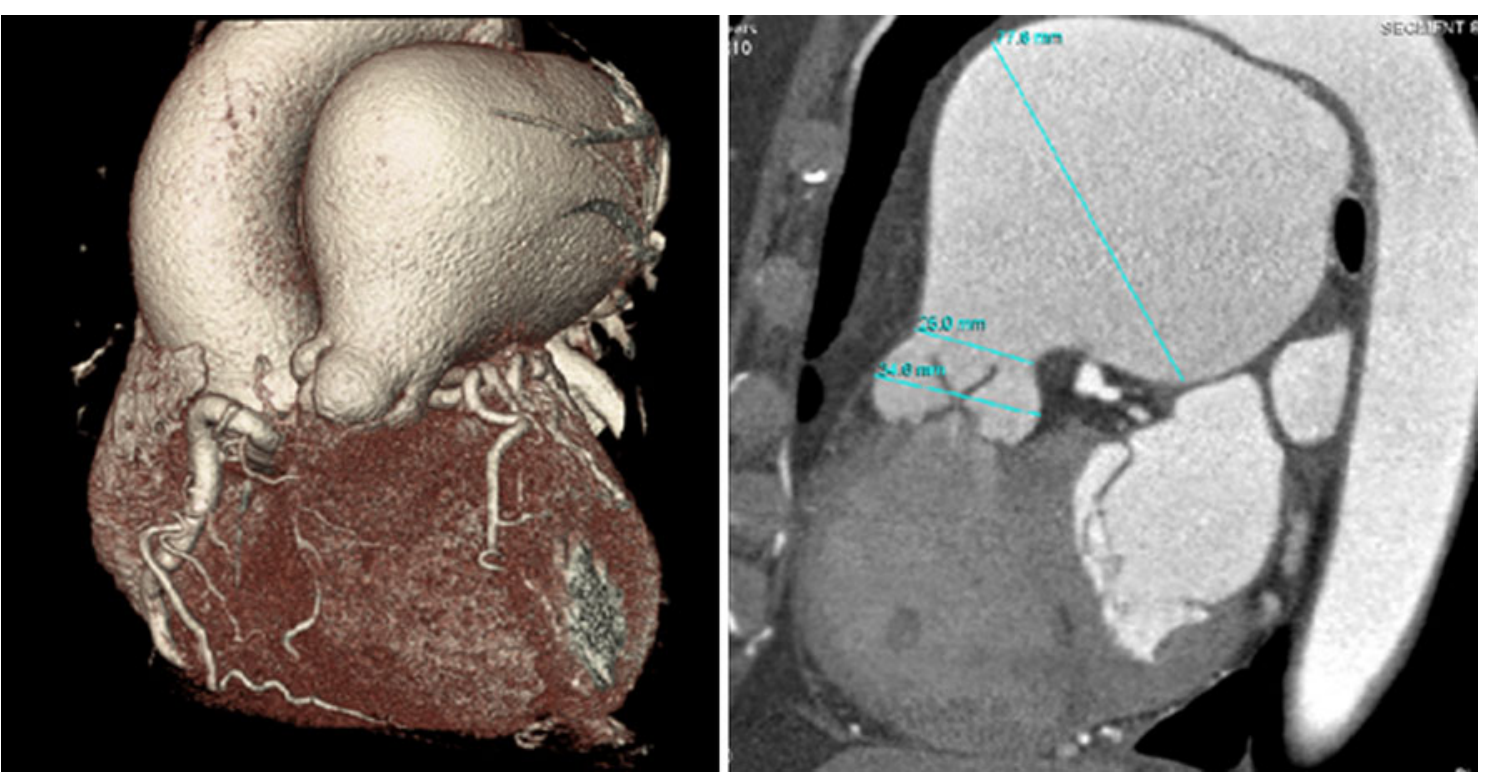

Fig. 2 Computed tomography: visualization of voluminous aneurysm of pulmonary artery

Although there are no clear guidelines for optimal treatment, surgery is indicated in patients at a risk of dissection or rupture. Hemoptysis generally indicates instability of the aneurysm, and indicates the need for surgical intervention [4]. The optimal elective surgical treatment is the resection of the aneurysm and graft replacement.

Alternatively, patients with $<60 \mathrm{~mm}$ aneurysms, low pulmonary pressure, absence of congenital or acquired significant right shunt or not associated with collagenopathies are considered at low risk, and conservative management is preferred [1-4].

2DE rules out pulmonary hypertension or pulmonary valve infection and intracardiac shunt as secondary causes of the aneurysm.

The CT images can provide more information than routine 2DE. In fact, multislice $\mathrm{CT}$ of the thorax provides excellent three-dimensional (3D) images that show the relationships of the mediastinal and thoracic structures to the aneurysm. Furthermore, it provides better definition of the morphologic characteristics of the cardiac chambers and pulmonary artery. So the information provided by the
CT to the surgical team is accurate because it is not based on verbal information and $3 \mathrm{D}$ mental reconstruction, but is rather a simple image, similar to what would be found in the operating room.

\section{Conflict of interest None.}

\section{References}

1. Vistarini N, Aubert S, Gandjbakhch I, Pavie A (2007) Surgical treatment of a pulmonary artery aneurysm. Eur J Cardiothorac Surg 31:1139-1141

2. Veldtman G, Dearani J, Warnes C (2003) Low pressure giant pulmonary artery aneurysms in the adult: natural history and management strategies. Heart 89:1067-1070

3. Deb S, Zehr K, Shields R (2005) Idiopathic pulmonary artery aneurysm. Ann Thorac Surg 80:1500-1502

4. Vural AH, Türk T, Ata Y, Göncü T, Ozyazicioglu A (2007) Idiopathic asymptomatic main pulmonary artery aneurysm: surgery or conservative management? A case report. Heart Surg Forum 10:E273-E275 